\title{
Reduction of NANOG Mediates the Inhibitory Effect of Aspirin on Tumor Growth and Stemness in Colorectal Cancer
}

\author{
Hefei Wang ${ }^{a, b, c}$ Bing Liu ${ }^{a}$ Jing Wang ${ }^{d, a}$ Jinglin Lie Ying Gong ${ }^{f}$ Sisi Li ${ }^{a}$ \\ Chunli Wang $^{a}$ Bai Cui ${ }^{a}$ Xiaoyuan Xue ${ }^{a}$ Mengying Yang ${ }^{a}$ Wenjun Fan ${ }^{a}$ \\ Zhijie Kang $^{g}$ Muhammad Kamran ${ }^{\mathrm{a}}$ Jie Xu ${ }^{\mathrm{a}}$ Pengfei Tian ${ }^{\mathrm{h}}$ Yuanyuan Luo \\ Zhijie Hou ${ }^{\mathrm{a}}$ Lin Dong ${ }^{\mathrm{a}}$ Yanling Ren ${ }^{\mathrm{h}}$ Man Lif ${ }^{\mathrm{f}}$ Qingping Wen ${ }^{\mathrm{e}}$ Wei Cheng ${ }^{\mathrm{a}}$ \\ Lingzhi Xu ${ }^{f}$ Ling Wang ${ }^{h}$ Quentin Liuba
}

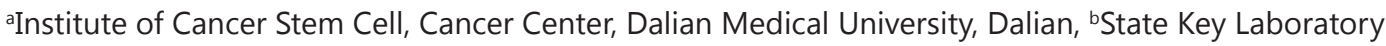
of Oncology in South China, Collaborative Innovation Center for Cancer Medicine, Sun Yat-sen University, Guangzhou, 'Department of Biochemistry and Molecular Biology, Harbin Medical University, Harbin, dDepartment of Oncology, The First Affiliated Hospital of Gannan Medical College, Ganzhou, eDepartment of Anesthesia, The First Affiliated Hospital, Dalian Medical University, Dalian, fDepartment of Oncology, The Second Affiliated Hospital, Dalian Medical University, Dalian, 9Department of Hematology, The Second Affiliated Hospital, Dalian Medical University, Dalian, hDepartment of Oncology, The First Affiliated Hospital, Dalian Medical University, Dalian, China
\end{abstract}

\section{Key Words}

Aspirin • Colorectal Cancer • Cancer Stem Cells • NANOG • Protein Stabilization

\begin{abstract}
Background/Aims: Cancer stem cells (CSCs) are considered to be responsible for tumor relapse and metastasis, which serve as a potential therapeutic target for cancer. Aspirin has been shown to reduce cancer risk and mortality, particularly in colorectal cancer. However, the CSCssuppressing effect of aspirin and its relevant mechanisms in colorectal cancer remain unclear. Methods: CCK8 assay was employed to detect the cell viability. Sphere formation assay, colony formation assay, and ALDH1 assay were performed to identify the effects of aspirin on CSC properties. Western blotting was performed to detect the expression of the stemness factors. Xenograft model was employed to identify the anti-cancer effects of aspirin in vivo. Unpaired Student $t$ test, ANOVA test and Kruskal-Wallis test were used for the statistical comparisons. Results: Aspirin attenuated colonosphere formation and decreased the ALDH1 positive cell population of colorectal cancer cells. Aspirin inhibited xenograft tumor growth and reduced tumor cells stemness in nude mice. Consistently, aspirin decreased the protein expression of stemness-related transcription factors, including c-Myc, OCT4 and NANOG. Suppression of NANOG blocked the effect of aspirin on sphere formation. Conversely, ectopic expression of NANOG rescued the aspirin-repressed sphere formation, suggesting that NANOG is a key downstream target. Moreover, we found that aspirin repressed NANOG expression in

H. Wang, B. Liu, J. Wang and J. Li contributed equally to this work.

\begin{tabular}{ll}
\hline Q Liu, L Wang, LZ Xu and & Institute Cancer Stem Cell, Dalian Medical University, Dept Oncol, The First Affiliated Hospital, \\
W Cheng & Dalian Medical University, Dept Oncol, The Second Affiliated Hospital, Dalian Medical University, \\
& Institute Cancer Stem Cell, Dalian Medical University (China); \\
& E-Mail liuq9@mail.sysu.edu.cn/Whwl@hotmail.com/xvlingzhi@sina.com/wcheng@dmu.edu.cn
\end{tabular}


protein level by decreasing its stability. Conclusion: We have provided new evidence that aspirin attenuates CSC properties through down-regulation of NANOG, suggesting aspirin as a promising therapeutic agent for colorectal cancer treatment.

(C) 2017 The Author(s)

Published by S. Karger AG, Basel

\section{Introduction}

Colorectal cancer is the third leading cause of cancer death and the incidence still maintains as a rapid increase in developing countries [1]. Although conventional approaches have improved survival [2,3], a number of patients get feeble benefit from the conventional therapy strategies owing to drug resistance, tumor relapse and metastasis [4]. Colorectal CSCs, which display unlimited self-renewal ability [5], are responsible for tumor relapse [68]. Colorectal CSCs are characterized by the expression of biomarkers; LGR5 ${ }^{+}$[9], EphB2 ${ }^{\text {high }}$ [10], CD44v6 $6^{+}[11], \mathrm{ALDH}^{+}[12]$ and OCT- $4^{+}[13]$.

Aspirin, also known as acetylsalicylic acid (ASA), has been widely used in the treatment of pain, fever, and inflammation. Aspirin has been shown to be a potential agent for cancer chemoprevention, especially in colorectal cancer $[14,15]$, by inducing cancer cell apoptosis and inhibiting cell proliferation $[16,17]$. Recently, aspirin has attracted strong attention for its effect on metastasis inhibition [18-21] and chemotherapy sensitivity improvement [22, 23]. Moreover, aspirin inhibits cancer cells proliferation and induces cancer cell apoptosis by preventing NF- $\kappa B$ activation [24, 25], interfering with ERK pathway [26] and inhibiting Wnt/ $\beta$-catenin pathway [27]. However, the mechanism underlying the anti-CSCs effects of aspirin remains unknown.

NANOG serves as a key regulator in both embryonic and cancer stem cells [28]. Overexpression of NANOG is associated with poor prognosis in several malignancies, including breast, colorectal and ovarian cancer [29-31]. An epidemiological study indicated that NANOG protein may be an independent biomarker for poor prognosis of colorectal cancer [31]. NANOG was reported to play a critical role in CRC stemness maintenance. Consistently, gene depletion of NANOG in colorectal cancer cell lines attenuates spheres formation ability and hampered tumorigenicity [32]. Conversely, overexpression of NANOG in colorectal cancer cells resulted in an increase in clonogenic potential and tumor formation in xenograft models [33].

There have been some studies on exploring the molecular mechanism for NANOG. An intriguing study demonstrated that depletion of NANOG reduced expression level of cyclinD1 through binding to its promoter region, blocking the cell cycle at G0/G1 phase [34]. In addition, NANOG was shown to promote EMT through its regulation of Slug [35] and E-cadherin [36]. There is considerable evidence that aspirin modulate the NANOG downstream gene. Furthermore, aspirin was reported to suppress cyclin D1 expression to induce cell cycle arrest at G0/G1 phase [37]. Aspirin impedes p65 translocation and result in down-regulation of Slug and thereby up-regulation of E-cadherin [38]. These findings indicate that aspirin may have some effect on NANOG regulation.

In the present study, we showed that aspirin suppressed colorectal cancer cells viability in vitro and in vivo at tolerable concentration. We demonstrated that aspirin attenuated colorectal CSC properties through repressing NANOG. Moreover, aspirin reduced the stability of NANOG protein. These results indicated that aspirin was a potential agent for cancer treatment by targeting CSCs.

\section{Materials and Methods}

Cell culture

HCT116 cells were purchased from the American Type Culture Collection (ATCC). LoVo and RKO cells were provided by Prof. Wuguo Deng (Sun Yat-sen University, Guangzhou, China). HCT116 cells were cultured in McCoy's 5a medium (Invitrogen Corp.) containing 10\% fetal bovine serum (FBS, GIBCO). LoVo cells were maintained in RPMI-1640 medium (Invitrogen Corp) containing 10\% fetal bovine serum (FBS, 


\section{Cellular Physiology Cell Physiol Biochem 2017;44:1051-1063 \begin{tabular}{l|l|l} 
and Biochemistry 10.1159/000485405 & $\begin{array}{l}\text { C) } 2017 \text { The Author(s). Published by S. Karger AG, Basel } \\
\text { www.karger.com/cpb }\end{array}$ \\
\hline
\end{tabular}}

Wang et al.: ASA Attenuates CSCs Property though NANOG

GIBCO). RKO cells were cultured in Eagle's Minimum Essential Medium (Invitrogen Corp) containing 10\% fetal bovine serum (FBS, GIBCO).

\section{CCK-8 assay}

HCT116, LoVo and RKO cells were seeded in 96-well microplates and cultured with various doses of aspirin for 24, 72 and $120 \mathrm{~h}$. CCK-8 solution (Dojindo) was added to the cells, and the cells were incubated for another $3 \mathrm{~h}$ at $37^{\circ} \mathrm{C}$. The optical density (OD) was measured at an absorbance of $450 \mathrm{~nm}$.

\section{Sphere formation assay}

Cells were seeded in 24-well ultra-low attachment plates $\left(1 \times 10^{3}\right.$ cells/well $)$ and maintained in DMEM/F12 (Gibco) supplemented with $20 \mathrm{ng} / \mathrm{ml}$ epithelial growth factor (EGF, Sigma-Aldrich), $20 \mathrm{ng} /$ $\mathrm{ml}$ basic fibroblast growth factor (bFGF, BD Biosciences) and B27 (Invitrogen) for 7-10 days. The spheres were photographed using an inverted microscope (Olympus). Spheres larger than $50 \mu \mathrm{m}$ in diameter were counted.

\section{Colony formation assay}

Approximately $1 \times 10^{3}$ cells were plated into $6 \mathrm{~mm}^{3}$ dishes and treated with aspirin or DMSO. After 1014 days, the cells were fixed in 4\% PFA and stained with a $0.05 \%$ crystal violet solution (Sigma-Aldrich).

\section{ALDEFLUOR assay}

For the ALDH assay, cells were identified using the ALDEFLUOR reagent kit (STEMCELL, \#01700). Cells were suspended in ALDEFLUOR assay buffer at a concentration of $1 \times 10^{6}$ cells $/ \mathrm{ml}$ and divided into two tubes labeled "control" and "test". Diethylaminobenzaldehyde (DEAB), a specific ALDH inhibitor, was added to the control tube to control for background fluorescence. Activated ALDEFLUOR reagent was added to both tubes. The tubes were incubated for 30 minutes at $37^{\circ} \mathrm{C}$, and the tubes were then centrifuged for 5 minutes at 250 g. Cell pellets were resuspended in ALDEFLUOR assay buffer and stored on ice. The ALDH1-positive subpopulation was detected by FACS.

\section{Western blot analysis}

Cellular proteins were extracted using RIPA buffer supplemented with the protease inhibitor PMSF and the protease inhibitor cocktail (MCE). The protein concentration was measured by Bradford assay. Equal amounts of cellular proteins were loaded to separate in 8-15\% SDS-PAGE and then transferred to nitrocellulose membranes (Millipore) via submerged transfer. After blocking, the membranes were incubated with various primary antibodies at $4^{\circ} \mathrm{C}$ overnight. Next, the membranes were incubated for 1 hour at RT with the appropriate secondary antibodies. Proteins were visualized using an enhanced chemiluminescence kit (Advansta).

The following antibodies were used: NANOG (Abcam \#80892, Cell Signaling Technology \#4903S), $\beta$-catenin, c-Myc (Cell Signaling Technology \#5605S), SOX2 (Cell Signaling Technology \#3579S), OCT4 (Cell Signaling Technology \#2750S), E-Cadherin (Cell Signaling Technology \#4065), N-Cadherin (Cell Signaling Technology \#13116), Vimentin (Cell Signaling Technology \#5741), Flag (Sigma-Aldrich \#F2555), GAPDH (Kang Chen bio-tech \# KC-5G4), CD133 (Cell Signaling Technology \#64326), and CD44 (Cell Signaling Technology \#3570).

\section{Tumor growth in xenografts}

All animal studies were approved by the Institutional Animal Care and Use Committee of Dalian Medical University and were carried out in accordance with national and international guidelines for the care and maintenance of laboratory animals. HCT116 cells were suspended in McCoy's 5a medium supplemented with 50\% Matrigel (BD Biosciences) and then injected into BALB/c nude male mice (four to six weeks old) subcutaneously. On day 5, the mice were randomly divided into two groups, and aspirin or vehicle control was administered intragastrically once daily. Tumor volumes were estimated using calipers once every three days according to the following formula: $\left(A \times B^{2}\right) / 2$, where $A$ is the greatest diameter, and $B$ is the diameter perpendicular to A. After administering aspirin or vehicle for 21 days, the tumor xenografts were harvested from euthanized mice and then weighed. The tumor xenografts were stored in liquid nitrogen for subsequent western blotting. 
Gene knockdown by short-hairpin RNA

The sequences of the shRNA constructs targeting NANOG (1\#, 2\#) are as follows: 1\#ACAGCAGACCACTAGGTATTTCTCGAGAAATACCTAGTGGTCTGCTGTTTTTTG and 2\#AGATGAGTGAAACTGATATTACTCGAGTAATATCAGTTTCACTCATCTTTTTTG. The above fragments were cloned into pLKO-tetO-shNC.

pFLAG-CMV2-NANOG was a gift from Prof. Lingqiang Zhang (Dalian Medical University, Dalian, China).

\section{Real-time quantitative PCR}

Total RNA was extracted using TRIzol reagent (Life Technologies, 15596026). The EasyScript One-Step gDNA Removal and cDNA Synthesis SuperMix kit (TransGene Biotech, \#AE311-03) was used to generate cDNA. Real-time PCR was performed using Platinum SYBR Green qPCR SuperMix (Invitrogen). Each sample was detected with three pairs of NANOG primers. GAPDH was used as an internal control for normalization.

\section{Statistics}

Each experiment was performed at least three times. Statistical tests were performed using SPSS Statistical 17.0. An unpaired Student's t test was used for statistical comparisons between two groups. One-way ANOVA followed by the least significant difference test was used for multiple comparisons. The Kruskal-Wallis test was used for statistical comparisons of data with non-normal distributions. All data are expressed as the mean \pm standard error (S.D.). A $p$ value less than 0.05 was considered statistically significant $\left({ }^{*} p<0.05,{ }^{* *} p<0.01,{ }^{* * *} p<0.001\right)$.

\section{Results}

\section{Aspirin inhibits cell viability in colorectal cancer cells}

To determine the effective inhibitory concentration of aspirin, colorectal cancer cells were treated with different doses of aspirin for $120 \mathrm{~h}$. CCK8 assays showed that the 50\%

Fig. 1. Aspirin inhibits the viability of colorectal cancer cells. (A) The IC50s of ASA were measured by sigmoidal curve fitting in HCT116 (a), LoVo (b) and RKO (c) cells. (B) HCT116 (a), LoVo (b) and RKO (c) cells were treated with increasing concentrations of ASA (from $0.625 \mathrm{mM}$ to $5 \mathrm{mM}$ ). After 24,72 and 120 h of incubation, cell viability was measured by CCK-8 assay.

A
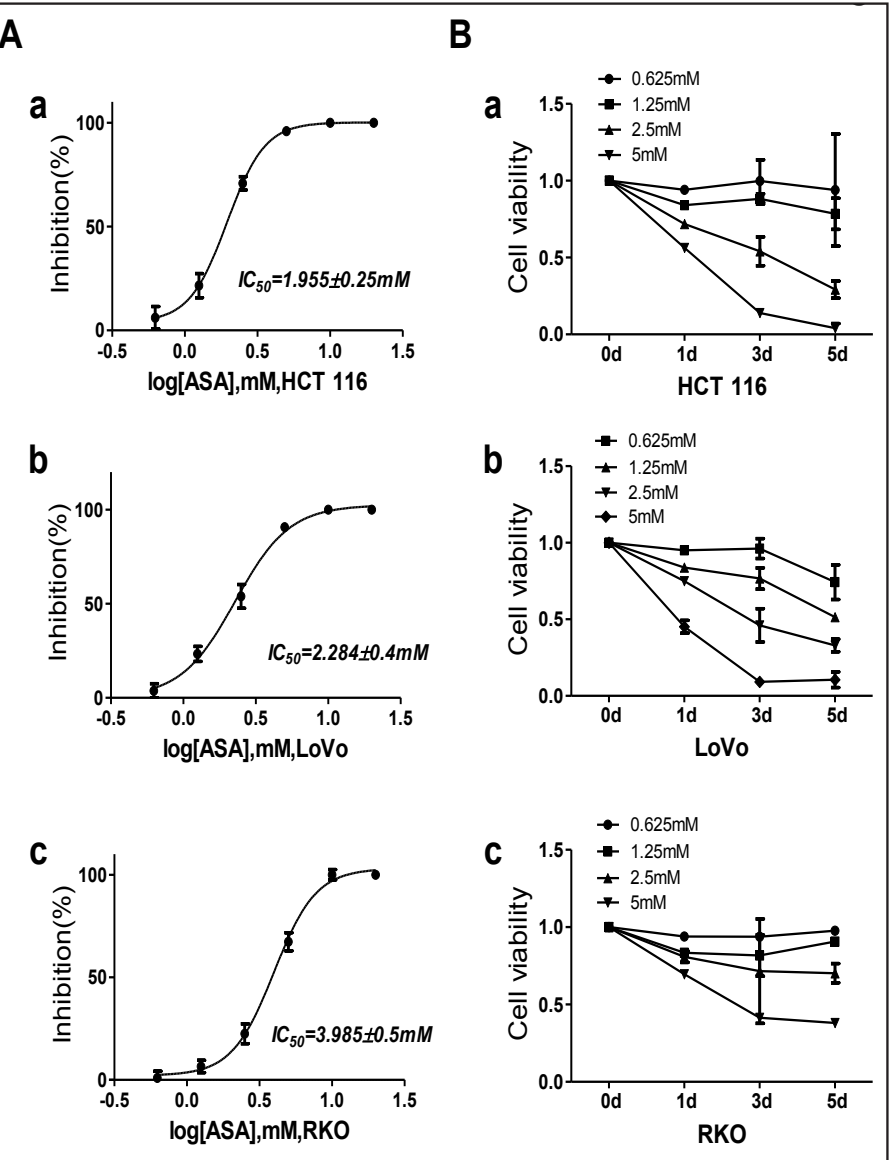
Fig. 2. Aspirin attenuates CSC properties in colorectal cancer cells. (A) HCT116 (a) and LoVo (b) cells were plated in low-serum, non-adherent culture conditions and treated with various concentrations of ASA. Images were obtained after 7 days in culture. Sphere number and size are shown. The data are expressed as the mean \pm S.D. of three independent experiments ${ }^{*} \mathrm{p}<0.05,{ }^{* *} \mathrm{p}<0.01$, $* * * \mathrm{p}<0.001$, Student's $t$ test). (B) Dissociated HCT116 (a) and LoVo (b) cells were seeded in 6-cm dishes and treated with the indicated concentrations of ASA. Representative images of the colonies were captured. The data are expressed as the mean \pm S.D. of three independent experiments $\quad(* * \mathrm{p}<0.01$, ${ }^{* * *} \mathrm{p}<0.001$, Student's t test). (C) The ratio of ALDH1-positive cells in HCT116 (a) and LoVo (b) cells untreated or treated with ASA for 7 days are shown. The data are expressed as the mean \pm S.D. of three independent experiments ( ${ }^{*} \mathrm{p}<0.05,{ }^{* *} \mathrm{p}<0.01$, Student's t test).

inhibitory concentration (IC50) of aspirin for HCT116, LoVo, and RKO cells were $1.955 \pm 0.25$, $2.284 \pm 0.4$ and $3.985 \pm 0.5 \mathrm{mM}$, respectively (Fig $1 \mathrm{~A}$ ). In addition, dose levels of aspirin at 1-5mM are ideal for clinical anti-inflammation treatment [39]. Thus, subsequent studies were carried out at the $1.25 \mathrm{mM}$ and $2.5 \mathrm{mM}$. To evaluate the effect of aspirin on colorectal cancer cells viability, the colorectal cancer cell lines were treated with a different concentration and time gradient. We observed that aspirin reduced cell viability in a dose- and time-dependent manner (Fig. 1B). These results indicated that aspirin inhibited the cell viability of colorectal cancer cells.
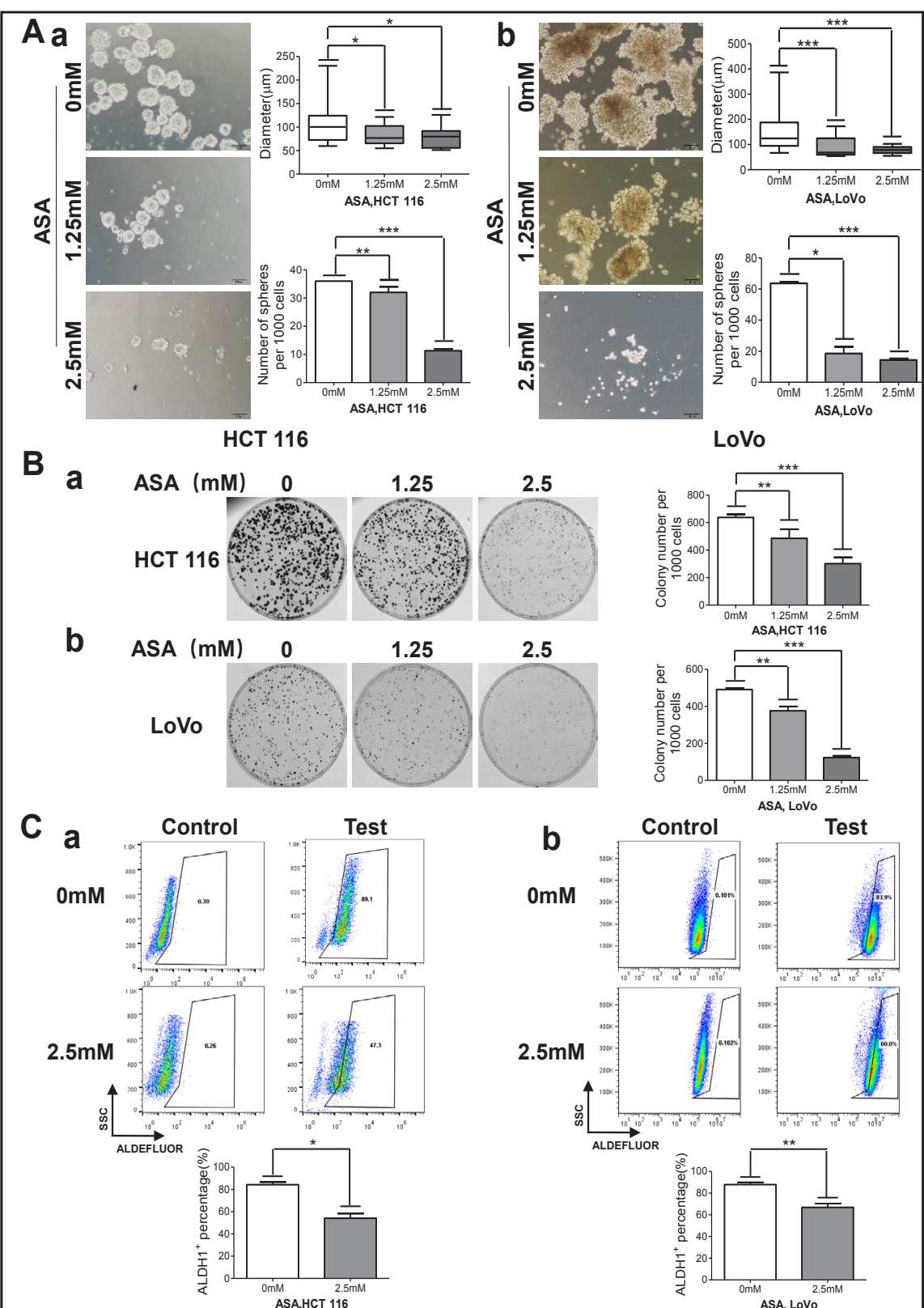

LoVo

$$
\text { . }
$$




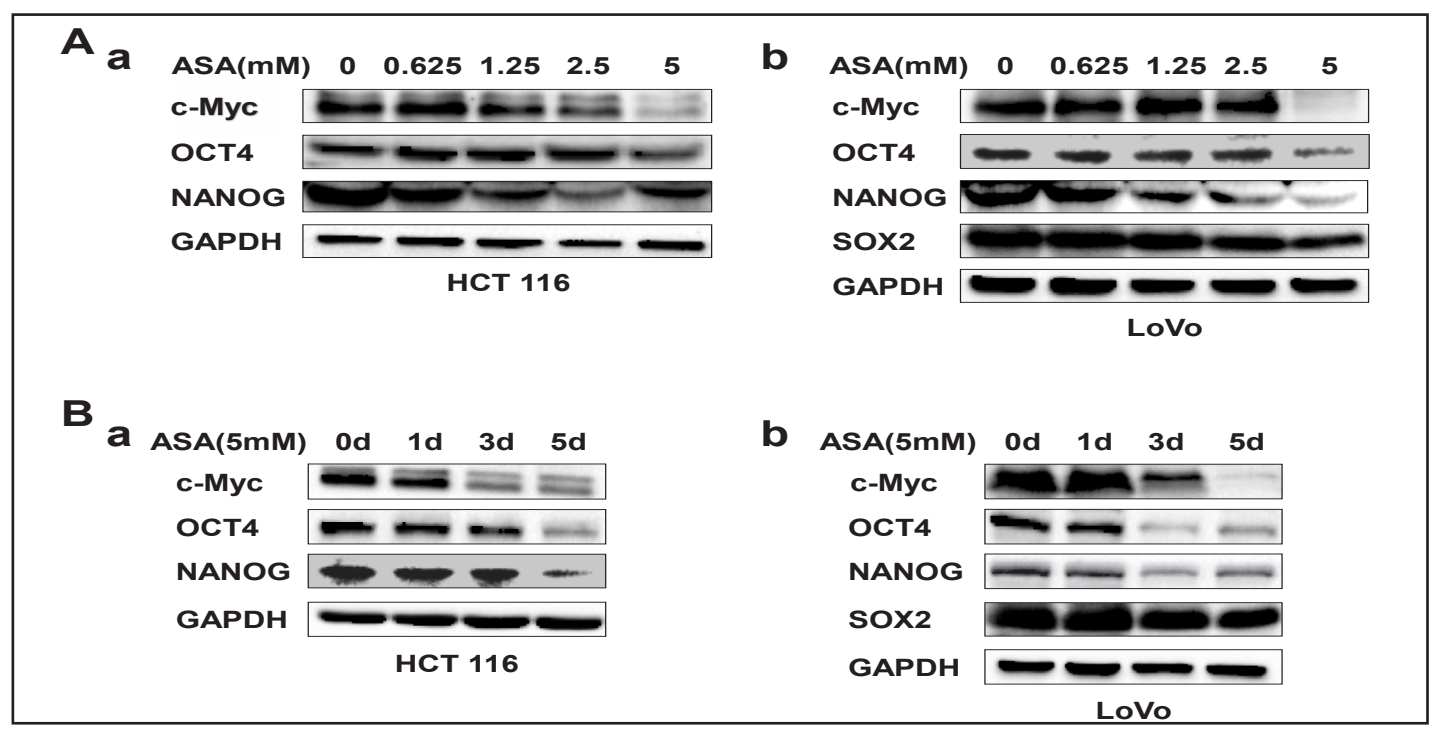

Fig. 3. Aspirin suppresses the expression of stemness factors.(A-B) HCT116 and LoVo cells were treated with various concentrations of ASA for $48 \mathrm{~h} \mathrm{(A)}$ and with $5 \mathrm{mM}$ ASA for 1,3 or 5 days (B). The lysates were subjected to western blotting to determine the expression levels of c-Myc, OCT4, SOX2 and NANOG. GAPDH served as the loading control.

Aspirin attenuates cancer stem cell properties in colorectal cancer cells

To identify the effects of aspirin on CSC properties, we performed sphere formation, colony formation and ALDH1-positive assays in colorectal cancer cells. Compared with controls, the spheres size of aspirin groups was smaller when cultured with $1.25 \mathrm{mM}$ and $2.5 \mathrm{mM}$ aspirin. The number of spheres which diameter larger than $50 \mu \mathrm{m}$ were decreased by treating with aspirin (Fig. 2Aa). Similar results were observed in LoVo cells (Fig. 2Ab). To gain further evidence about the effects of aspirin on CSC properties, colony formation assay was performed. Aspirin significantly decreased the colony formation number in HCT 116 cells, LoVo cells (Fig. 2B). Next, we used flow cytometry to investigate whether aspirin attenuated CSC properties based on ALDEFLUOR assay [40]. As expected, aspirin decreased the ratio of ALDH1 positive cells by approximately $30 \%$ after treating with $2.5 \mathrm{mM}$ aspirin for 7 days (Fig. 2C). Collectively, these results suggested that aspirin attenuated CSC properties in colorectal cancer cells.

\section{Aspirin suppresses the expression of stemness factors}

We detected the expression level of several stemness factors, including c-Myc, OCT4, NANOG and SOX2 [32, 41-43] by western blotting. Aspirin suppressed the stemness factors expression with increasing dose (Fig. 3A), whereas SOX2 expression could not be detected in HCT 116 cells. Next, we treated cells with $5 \mathrm{mM}$ aspirin, and detected the expression of stemness factors at 1, 3, 5 days. The expression levels of stemness factors were decreased with increasing time (Fig. 3B). These data indicated that aspirin may suppress CSC properties by decreasing the stemness factors expression.

\section{Aspirin inhibits xenograft tumor growth and tumor CSCs stemness}

We next identified the in vivo anti-cancer effects of aspirin by employing a xenograft model. Nude mice were injected subcutaneously with $5 \times 10^{5}$ HCT 116 cells and treated with DMSO or aspirin $(100 \mathrm{mg} / \mathrm{kg} / \mathrm{d})$ by intra-gastric administration. The tumor xenografts were harvested from euthanized mice after 21 days treatment. The tumor size was reduced in the aspirin-treated group compared to the DMSO-treated control group (Fig. 4A and 4B). We also observed that the tumor weight in aspirin-treated group was lower than that in DMSO-treated control group (Fig. 4C). In addition, there is no significant difference in body 


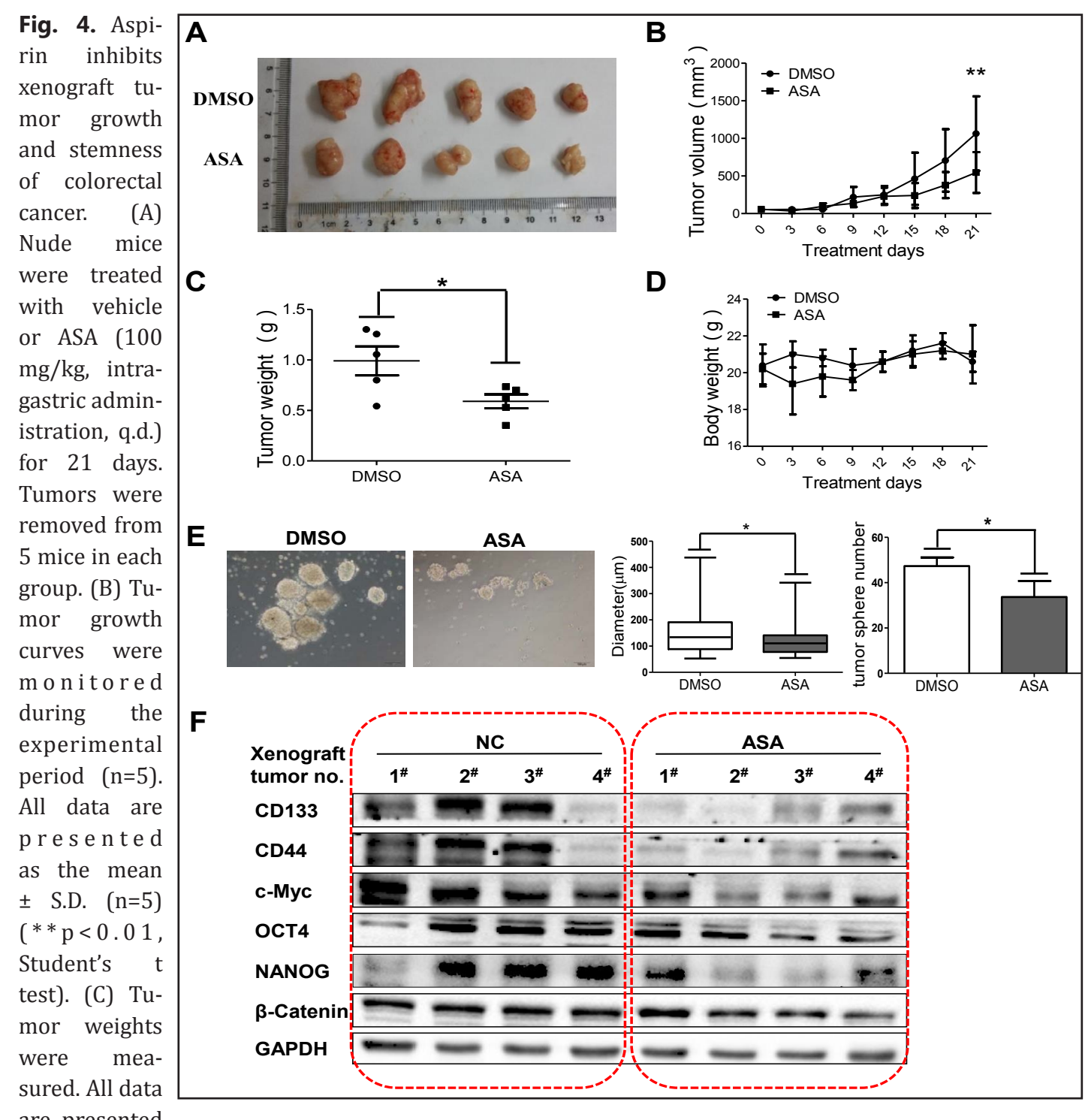

are presented

as the mean \pm S.D. $(n=5)\left({ }^{*} p<0.05\right.$, Student's t test). (D) The body weights were monitored and plotted versus time. All data are presented as the mean \pm S.D. $(n=5)$. (E) Representative images of sphere formation of primary culture cells after 7 days in culture showing sphere size and number. All data are presented as the mean \pm S.D. $(n=5)\left({ }^{*} \mathrm{p}<0.05\right.$, Student's t test). (F) Protein lysates obtained from xenograft tumors were analyzed by western blotting to detect the expression levels of CD133, CD44, c-Myc, OCT4, NANOG and $\beta$-Catenin. GAPDH served as the loading control.

weight between control group and aspirin-treated group (Fig. 4D). These results indicated that aspirin suppressed tumor growth and stemness meanwhile induced scarcely toxicity in xenograft model.

To investigate whether aspirin attenuated the stem cell properties of xenograft tumor, we performed sphere formation assay with the primary culture cells (Fig. 4E). Both the sphere size and sphere number in aspirin-treated group were smaller than that in DMSO-treated control group. Furthermore, the western blotting showed that the aspirin-treated xenograft tumors expressed lower levels of stemness markers as compared with the DMSO-treated control group (Fig. 4F). Collectively, these results demonstrated that aspirin inhibited tumor growth and CSCs stemness in xenograft tumors.

\section{KARGER}




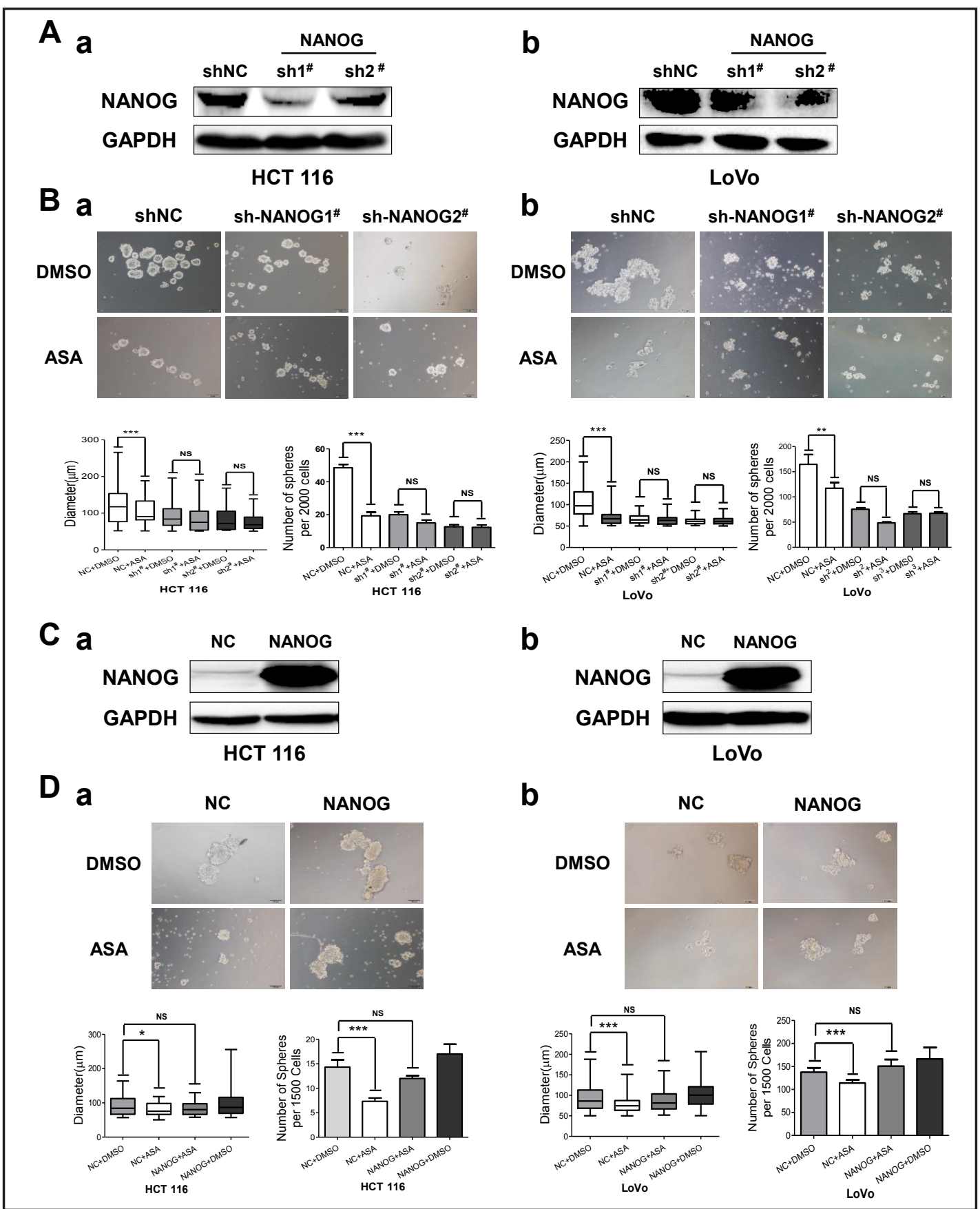

Fig. 5. Aspirin attenuates colorectal CSC properties by down-regulating NANOG. (A) NANOG knockdown was achieved through stable lentiviral-mediated short hairpin RNA interference (shRNA). NANOG protein expression levels in HCT116 (a) and LoVo (b) cells were measured by western blotting. GAPDH served as the loading control. (B) NANOG knockdown cells were incubated with ASA (2.5 mM) or DMSO for 7 days and photographed using an inverted microscope. The number and size of HCT116 (a) and LoVo (b) spheres are shown. The data are presented as the mean \pm S.D. of three independent experiments $\left(* * \mathrm{p}<0.01,{ }^{* * *} \mathrm{p}<0.001\right.$, Student's t test). (C) NANOG was overexpressed in HCT116 (a) and LoVo (b) cells. NANOG protein expression was measured by western blotting. GAPDH served as the loading control. (D) Cells expressing pFLAGCMV2-NANOG or vector were cultured with ASA (2.5 mM) or DMSO for 7 days and photographed using an inverted microscope. The number and size of HCT116 (a) and LoVo (b) spheres are shown. The data are presented as the mean \pm S.D. of three independent experiments $\left(* * p<0.01,{ }^{* * *} p<0.001\right.$, Student's t test).

\section{KARGER}


Fig. 6. Aspirin suppresses NANOG by decreasing its protein stability. (A) HCT116 cells were treated with increasing doses of ASA (from $0 \mathrm{mM}$ to 5 $\mathrm{mM}$ ) for $48 \mathrm{~h}$ and then subjected to western blotting. GAPDH served as the loading control. (B) The relative mRNA expression of NANOG in HCT116 cells treated with 0 or $5 \mathrm{mM}$ ASA for 48 h. (C) NANOG protein levels were analyzed at different time points after treatment with cycloheximide (CHX) in the presence or absence of ASA. NANOG protein expression was determined by western blotting. GAPDH served as the loading control. (D) HCT116 cells were treated with DMSO or ASA (5 mM). Eight hours prior to harvesting, these cells were treated with DMSO or MG132. NANOG protein expression was determined by western blotting. GAPDH served as the loading control.

Aspirin attenuates colorectal cancer stem cell properties through down-regulating NANOG

Previous studies have shown that NANOG plays key roles in maintenance of CSCs stemness [32]. We thus hypothesized that NANOG might play an important role in aspirininduced CSCs stemness suppression. NANOG knockdown was achieved through stable lentiviral-mediated short hairpin RNA interference (shRNA) (Fig. 5A). We treated control cells and NANOG knockdown cells with DMSO or aspirin for 7days. Aspirin has no effect on sphere formation in NANOG knockdown cells. Meanwhile, aspirin attenuated the sphere formation in control cells (Fig. 5B). To overexpress NANOG in cells, we used a wild-type flagtagged NANOG-encoding expression plasmid (Fig. 5C). We performed the sphere formation in cells with NANOG overexpression. We found that the impairment of aspirin on sphere formation was rescued by overexpressing NANOG (Fig. 5D). Collectively, these results suggest that aspirin attenuates CSC properties through NANOG downregulation in colorectal cancer.

\section{Aspirin suppresses NANOG by decreasing protein stability}

Next, we found that protein expression of NANOG was suppressed in cells treated with aspirin (Fig. 6A), while mRNA expression of NANOG was up-regulated (Fig. 6B). These results suggest that aspirin suppressed the expression of NANOG at protein level. To determine if the half-life of NANOG was shorter upon the aspirin treatment, we treated cells with protein synthesis inhibitor cycloheximide followed by either aspirin or DMSO. This revealed that the half-life of NANOG was significantly shorter when cells were treated with aspirin compared with DMSO (Fig. 6C). The repression of NANOG induced by aspirin was not rescued by treating with MG132, a proteasome inhibitor, suggesting that aspirin reduced NANOG expression via proteasome-independent pathway (Fig. 6D).

\section{Discussion}

Earlier studies of aspirin clarified significant effects for aspirin in anti-cancer therapy, including induction of apoptosis and chemotherapeutics sensibility, inhibition of proliferation 
and metastasis. Molecular mechanisms underlying anti-cancer effects were associated with inactivation of NF- $\kappa B, E R K$, MAPK and Wnt/ $\beta$-catenin pathways.

In this study, we provide new evidence that aspirin attenuates CSC properties through down-regulation of NANOG in colorectal cancer. We showed that aspirin inhibited colonosphere formation, decreased the ALDH1 positive cell population of colorectal cancer cells, down-regulated the protein expression of stemness-related transcription factors c-Myc, OCT4 and NANOG. Therefore, we demonstrated that aspirin attenuated CSC properties in colorectal cancer, which suggests a potential effect of aspirin in cancer therapy. Interestingly, aspirin has no effect on sphere formation ability in NANOG knockdown cells, and ectopic expression of NANOG rescued the aspirin-repressed sphere formation ability. Our finding indicated that NANOG plays an important role in aspirin induced inhibition of CSCs stemness. The present study suggested a compelling strategy in cancer treatment.

CSCs are considered to be responsible for tumor relapse and metastasis. Therefore, targeting CSCs is essential for complete tumor eradication. Thus, the therapeutic strategies targeting CSCs are effective. CSCs can be targeted by inhibiting relative pathways and factors. More and more CSCs targeting drugs have been explored in past and recent years [44], such as IWP and Pyrvinium, new small molecules which are able to inhibit Wnt/ $\beta$ catenin signaling pathway $[45,46]$. In addition, curcumin, piperine and sulforaphane have been shown to attenuate CSCs by suppressing Wnt signaling pathway [47-49]. Metformin selectively targets NF- $\mathrm{BB}$ and STAT3 to suppresses CSCs [50]. These results suggest that antiCSCs targeted drug can improve the therapeutic efficacy of cancer treatment.

Clinical, epidemiological, and experimental studies all indicate that aspirin possesses anticancer activities. Common anti-cancer effect of aspirin includes induction of apoptosis and inhibition of proliferation [51]. In recent years, aspirin is suggested to cause a change in cellular metabolism by inhibition of mTOR and active AMPK in colorectal cancer cells. In addition, several clinical and experimental studies support that aspirin inhibits metastasis which is a promising effect of aspirin $[18,19]$. Consistently, we proved that aspirin inhibits metastasis in colorectal cancer cells. Besides, it is reported that aspirin induces differentiation of several studies $[52,53]$. These results from our group and others suggested that aspirin inhibits metastasis and promote differentiation.

Our reports unveiled a novel mechanism underlying the anti-cancer effects of aspirin, thus aspirin attenuated colorectal CSC properties by NANOG down-regulation. For the first time we reported that aspirin repressed NANOG expression in protein level by decreasing the stability of NANOG. These data indicated that aspirin may be a potential agent for cancer therapy by targeting NANOG.

\section{Acknowledgements}

We thank Professor Lingqiang Zhang for kindly providing the pFLAG-CMV2-NANOG plasmids. We also thank Professor Wuguo Deng for providing the LoVo and RKO cells. This research work was supported by the National Basic Research Program of China (973 Program, No. 2012CB967000 to QL), Innovative Research Team in University of Ministry of Education of China (No. IRT13049), National Natural Science Foundation of China (No.81573025 to QL, No. 81402445 to C-LW, No. 81502579 to Z-JH), Liaoning (NSF2014029102 to QL) and Natural Science Foundation of Liaoning (No.2015020262 to JX), National Natural Science Foundation of China (No. 81602588 to Ling-Zhi Xu), the Liaoning (No. 201601231 to LingZhi Xu).

\section{Disclosure Statement}

The authors declare no conflict of interest. 


\section{Cellular Physiology Cell Physiol Biochem 2017;44:1051-1063 \begin{tabular}{l|l} 
and BOI: 10.1159/000485405 & $\begin{array}{l}\text { (O) 2017 The Author(s). Published by S. Karger AG, Basel } \\
\text { www.karger.com/cpb }\end{array}$
\end{tabular}}

Wang et al.: ASA Attenuates CSCs Property though NANOG

\section{References}

1 WHO: World Cancer Report 2014, 2014.

-2 Nagtegaal ID, Quirke P: What is the role for the circumferential margin in the modern treatment of rectal cancer? J Clin Oncol 2008;26:303-312.

- Papadimitriou CA, Papakostas P, Karina M, Malettou L, Dimopoulos MA, Pentheroudakis G, Samantas E, Bamias A, Miliaras D, Basdanis G, Xiros N, Klouvas G, Bafaloukos D, Kafiri G, Papaspirou I, Pectasides D, Karanikiotis C, Economopoulos T, Efstratiou I, Korantzis I, Pisanidis N, Makatsoris T, Matsiakou F, Aravantinos G, Kalofonos HP, Fountzilas G: A randomized phase III trial of adjuvant chemotherapy with irinotecan, leucovorin and fluorouracil versus leucovorin and fluorouracil for stage II and III colon cancer: a Hellenic Cooperative Oncology Group study. BMC Med 2011;9:10.

4 Gray R, Barnwell J, McConkey C, Hills RK, Williams NS, Kerr DJ: Adjuvant chemotherapy versus observation in patients with colorectal cancer: a randomised study. Lancet 2007;370:2020-2029.

-5 O'Brien CA, Pollett A, Gallinger S, Dick JE: A human colon cancer cell capable of initiating tumour growth in immunodeficient mice. Nature 2007;445:106-110.

6 Colak S, Zimberlin CD, Fessler E, Hogdal L, Prasetyanti PR, Grandela CM, Letai A, Medema JP: Decreased mitochondrial priming determines chemoresistance of colon cancer stem cells. Cell Death Differ 2014;21:1170-1177.

7 Dylla SJ, Beviglia L, Park IK, Chartier C, Raval J, Ngan L, Pickell K, Aguilar J, Lazetic S, Smith-Berdan S, Clarke MF, Hoey T, Lewicki J, Gurney AL: Colorectal cancer stem cells are enriched in xenogeneic tumors following chemotherapy. PLoS One 2008;3:e2428.

8 Ricci-Vitiani L, Lombardi DG, Pilozzi E, Biffoni M, Todaro M, Peschle C, De Maria R: Identification and expansion of human colon-cancer-initiating cells. Nature 2007;445:111-115.

-9 Kemper K, Prasetyanti PR, De Lau W, Rodermond H, Clevers H, Medema JP: Monoclonal antibodies against Lgr5 identify human colorectal cancer stem cells. Stem Cells 2012;30:2378-2386.

10 Jung P, Sato T, Merlos-Suarez A, Barriga FM, Iglesias M, Rossell D, Auer H, Gallardo M, Blasco MA, Sancho E, Clevers H, Batlle E: Isolation and in vitro expansion of human colonic stem cells. Nat Med 2011;17:12251227.

11 Todaro M, Gaggianesi M, Catalano V, Benfante A, Iovino F, Biffoni M, Apuzzo T, Sperduti I, Volpe S, Cocorullo G, Gulotta G, Dieli F, De Maria R, Stassi G: CD44v6 is a marker of constitutive and reprogrammed cancer stem cells driving colon cancer metastasis. Cell Stem Cell 2014;14:342-356.

12 Huang EH, Hynes MJ, Zhang T, Ginestier C, Dontu G, Appelman H, Fields JZ, Wicha MS, Boman BM: Aldehyde dehydrogenase 1 is a marker for normal and malignant human colonic stem cells (SC) and tracks SC overpopulation during colon tumorigenesis. Cancer Res 2009;69:3382-3389.

13 Tica Sedlar I, Petricevic J, Saraga-Babic M, Pintaric I, Vukojevic K: Apoptotic pathways and stemness in the colorectal epithelium and lamina propria mucosae during the human embryogenesis and carcinogenesis. Acta Histochem 2016;118:693-703.

14 Drew DA, Cao Y, Chan AT: Aspirin and colorectal cancer: the promise of precision chemoprevention. Nat Rev Cancer 2016;16:173-186.

15 Usman MW, Luo F, Cheng H, Zhao JJ, Liu P: Chemopreventive effects of aspirin at a glance. Biochim Biophys Acta 2015;1855:254-263.

-16 Tian Y, Ye Y, Gao W, Chen H, Song T, Wang D, Mao X, Ren C: Aspirin promotes apoptosis in a murine model of colorectal cancer by mechanisms involving downregulation of IL-6-STAT3 signaling pathway. Int J Colorectal Dis 2011;26:13-22.

17 Ding JH, Yuan LY, Huang RB, Chen GA: Aspirin inhibits proliferation and induces apoptosis of multiple myeloma cells through regulation of Bcl-2 and Bax and suppression of VEGF. Eur J Haematol 2014;93:329339.

18 Liao D, Zhong L, Duan T, Zhang RH, Wang X, Wang G, Hu K, Lv X, Kang T: Aspirin Suppresses the Growth and Metastasis of Osteosarcoma through the NF-kappaB Pathway. Clin Cancer Res 2015;21:5349-5359.

19 Rothwell PM, Wilson M, Price JF, Belch JF, Meade TW, Mehta Z: Effect of daily aspirin on risk of cancer metastasis: a study of incident cancers during randomised controlled trials. Lancet 2012;379:1591-1601.

20 Ogawa F, Amano H, Ito Y, Matsui Y, Hosono K, Kitasato H, Satoh Y, Majima M: Aspirin reduces lung cancer metastasis to regional lymph nodes. Biomed Pharmacother 2014;68:79-86. 


\section{Cellular Physiology Cell Physiol Biochem 2017;44:1051-1063

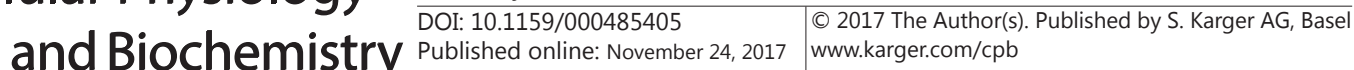

Wang et al.: ASA Attenuates CSCs Property though NANOG

-21 Shi C, Zhang N, Feng Y, Cao J, Chen X, Liu B: Aspirin Inhibits IKK-beta-mediated Prostate Cancer Cell Invasion by Targeting Matrix Metalloproteinase-9 and Urokinase-Type Plasminogen Activator. Cell Physiol Biochem 2017;41:1313-1324.

22 Moon CM, Kwon JH, Kim JS, Oh SH, Jin Lee K, Park JJ, Pil Hong S, Cheon JH, Kim TI, Kim WH: Nonsteroidal anti-inflammatory drugs suppress cancer stem cells via inhibiting PTGS2 (cyclooxygenase 2) and NOTCH/ HES1 and activating PPARG in colorectal cancer. Int J Cancer 2014;134:519-529.

-23 Bratasz A, Selvendiran K, Wasowicz T, Bobko A, Khramtsov VV, Ignarro LJ, Kuppusamy P: NCX-4040, a nitric oxide-releasing aspirin, sensitizes drug-resistant human ovarian xenograft tumors to cisplatin by depletion of cellular thiols. J Transl Med 2008;6:9.

-24 Kopp E, Ghosh S: Inhibition of NF-kappa B by sodium salicylate and aspirin. Science 1994;265:956-959.

-25 McCarty MF, Block KI: Preadministration of high-dose salicylates, suppressors of NF-kappaB activation, may increase the chemosensitivity of many cancers: an example of proapoptotic signal modulation therapy. Integr Cancer Ther 2006;5:252-268.

26 Pan MR, Chang HC, Hung WC: Non-steroidal anti-inflammatory drugs suppress the ERK signaling pathway via block of Ras/c-Raf interaction and activation of MAP kinase phosphatases. Cell Signal 2008;20:11341141.

27 Bos CL, Kodach LL, van den Brink GR, Diks SH, van Santen MM, Richel DJ, Peppelenbosch MP, Hardwick JC: Effect of aspirin on the Wnt/beta-catenin pathway is mediated via protein phosphatase 2A. Oncogene 2006;25:6447-6456.

28 Guo ZK, Guo K, Luo H, Mu LM, Li Q, Chang YQ: The expression analysis of nanog in the developing rat myocardial tissues. Cell Physiol Biochem 2015;35:866-874.

29 Nagata T, Shimada Y, Sekine S, Hori R, Matsui K, Okumura T, Sawada S, Fukuoka J, Tsukada K: Prognostic significance of NANOG and KLF4 for breast cancer. Breast Cancer 2014;21:96-101.

-30 Lee M, Nam EJ, Kim SW, Kim S, Kim JH, Kim YT: Prognostic impact of the cancer stem cell-related marker NANOG in ovarian serous carcinoma. Int J Gynecol Cancer 2012;22:1489-1496.

-31 Meng HM, Zheng P, Wang XY, Liu C, Sui HM, Wu SJ, Zhou J, Ding YQ Li J: Over-expression of Nanog predicts tumor progression and poor prognosis in colorectal cancer. Cancer Biol Ther 2010;9:295-302.

-32 Zhang J, Espinoza LA, Kinders RJ, Lawrence SM, Pfister TD, Zhou M, Veenstra TD, Thorgeirsson SS, Jessup JM: NANOG modulates stemness in human colorectal cancer. Oncogene 2013;32:4397-4405.

-33 Ibrahim EE, Babaei-Jadidi R, Saadeddin A, Spencer-Dene B, Hossaini S, Abuzinadah M, Li N, Fadhil W, Ilyas M, Bonnet D, Nateri AS: Embryonic NANOG activity defines colorectal cancer stem cells and modulates through AP1- and TCF-dependent mechanisms. Stem Cells 2012;30:2076-2087.

34 Han J, Zhang F, Yu M, Zhao P, Ji W, Zhang H, Wu B, Wang Y, Niu R: RNA interference-mediated silencing of NANOG reduces cell proliferation and induces G0/G1 cell cycle arrest in breast cancer cells. Cancer Lett 2012;321:80-88.

35 Chiou SH, Wang ML, Chou YT, Chen CJ, Hong CF, Hsieh WJ, Chang HT, Chen YS, Lin TW, Hsu HS, Wu CW: Coexpression of Oct4 and Nanog enhances malignancy in lung adenocarcinoma by inducing cancer stem cell-like properties and epithelial-mesenchymal transdifferentiation. Cancer Res 2010;70:10433-10444.

-36 Siu MKY, Wong ESY, Kong DSH, Chan HY, Jiang L, Wong OGW, Lam EWF, Chan KKL, Ngan HYS, Le XF, Cheung AN: Stem cell transcription factor NANOG controls cell migration and invasion via dysregulation of E-cadherin and FoxJ1 and contributes to adverse clinical outcome in ovarian cancers. Oncogene 2013;32:3500-3509.

37 Hu H, Zhang S, Zhu S: Influence of aspirin and cigarette smoke extract on the expression of cyclin D1 and effects of cell cycle in esophageal squamous cell carcinoma cell line. Dis Esophagus 2009;22:310-316.

38 Khan P, Manna A, Saha S, Mohanty S, Mukherjee S, Mazumdar M, Guha D, Das T: Aspirin inhibits epithelialto-mesenchymal transition and migration of oncogenic K-ras-expressing non-small cell lung carcinoma cells by down-regulating E-cadherin repressor Slug. BMC Cancer 2016;16:39.

39 Dovizio M, Bruno A, Tacconelli S, Patrignani P: Mode of action of aspirin as a chemopreventive agent. Recent Results Cancer Res 2013;191:39-65.

40 Douville J, Beaulieu R, Balicki D: ALDH1 as a functional marker of cancer stem and progenitor cells. Stem Cells Dev 2009;18:17-25.

41 Gabay M, Li Y, Felsher DW: MYC activation is a hallmark of cancer initiation and maintenance. Cold Spring Harb Perspect Med 2014;4. 


\section{Cellular Physiology Cell Physiol Biochem 2017;44:1051-1063 \begin{tabular}{l|l|l} 
DOI: 10.1159/000485405 & O 2017 The Author(s). Published by S. Karger AG, Basel \\
and Biocherger.com/cpb
\end{tabular}}

Wang et al.: ASA Attenuates CSCs Property though NANOG

42 Zeineddine D, Hammoud AA, Mortada M, Boeuf H: The Oct4 protein: more than a magic stemness marker. Am J Stem Cells 2014;3:74-82.

43 Boumahdi S, Driessens G, Lapouge G, Rorive S, Nassar D, Le Mercier M, Delatte B, Caauwe A, Lenglez S, Nkusi E, Brohee S, Salmon I, Dubois C, del Marmol V, Fuks F, Beck B, Blanpain C: SOX2 controls tumour initiation and cancer stem-cell functions in squamous-cell carcinoma. Nature 2014;511:246-250.

44 Yin M, Yuan Y, Cui Y, Hong X, Luo H, Hu X, Tang M, Hescheler J, Xi J: Puerarin Suppresses the Self-Renewal of Murine Embryonic Stem Cells by Inhibition of REST-MiR-21 Regulatory Pathway. Cell Physiol Biochem 2015;37:527-536.

45 Chen B, Dodge ME, Tang W, Lu J, Ma Z, Fan CW, Wei S, Hao W, Kilgore J, Williams NS, Roth MG, Amatruda JF, Chen C, Lum L: Small molecule-mediated disruption of Wnt-dependent signaling in tissue regeneration and cancer. Nat Chem Biol 2009;5:100-107.

46 Thorne CA, Hanson AJ, Schneider J, Tahinci E, Orton D, Cselenyi CS, Jernigan KK, Meyers KC, Hang BI, Waterson AG, Kim K, Melancon B, Ghidu VP, Sulikowski GA, LaFleur B, Salic A, Lee LA, Miller DM, 3rd, Lee E: Small-molecule inhibition of Wnt signaling through activation of casein kinase 1alpha. Nat Chem Biol 2010;6:829-836.

47 Li Y, Wicha MS, Schwartz SJ, Sun D: Implications of cancer stem cell theory for cancer chemoprevention by natural dietary compounds. J Nutr Biochem 2011;22:799-806.

48 Kakarala M, Brenner DE, Korkaya H, Cheng C, Tazi K, Ginestier C, Liu S, Dontu G, Wicha MS: Targeting breast stem cells with the cancer preventive compounds curcumin and piperine. Breast Cancer Res Treat 2010;122:777-785.

49 Li Y, Zhang T, Korkaya H, Liu S, Lee HF, Newman B, Yu Y, Clouthier SG, Schwartz SJ, Wicha MS, Sun D: Sulforaphane, a dietary component of broccoli/broccoli sprouts, inhibits breast cancer stem cells. Clin Cancer Res 2010;16:2580-2590.

50 Hirsch HA, Iliopoulos D, Struhl K: Metformin inhibits the inflammatory response associated with cellular transformation and cancer stem cell growth. Proc Natl Acad Sci U S A 2013;110:972-977.

51 Smith T, Elwood P, Keating C, Rothwell P, Detering E, Freedman A, Langley R, Logan R, Phillips C, DeCensi A: The Aspirin Foundation Scientific Conference: the history, the present state and the future of aspirin prophylaxis. Ecancermedicalscience 2014;8:388.

52 Ricchi P, Pignata S, Di Popolo A, Memoli A, Apicella A, Zarrilli R, Acquaviva AM: Effect of aspirin on cell proliferation and differentiation of colon adenocarcinoma Caco-2 cells. Int J Cancer 1997;73:880-884.

53 Supino R, Mazzoni A, Formelli F: Effect of medroxyprogesterone acetate and of some antiinflammatory agents on mouse erythroleukemia cell differentiation. Tumori 1984;70:17-21. 